\title{
What is Blended Learning? A Multiple Case Study
}

\author{
Kim Ramadan \\ University of North Carolina Charlotte, USA
}

\begin{abstract}
The purpose of this study was to explore blended learning and traditional instruction in three fifth grade literacy classrooms. Themes and patterns were examined to reveal the following findings: limitations for reading online prevented students from using reading strategies taught in traditional reading classes; the wealth of information provided from the Internet posed both advantages and challenges; and support for teachers and students in a blended learning model was imperative to its success.
\end{abstract}

\section{Introduction}

The term "literacy" has changed and broadened in the last few decades, particularly with the information and technology revolution [1]. As society becomes more dependent on technology as our primary form of communication, we see young children interacting with video games, students taking online courses, and the Internet becoming the major source for information. Additionally, the rise of technology has changed the way people communicate with one another [2]. The increase of technology outside schools has forced teachers to integrate online learning within the school walls [3].

Curriculum using primarily traditional print is no longer sufficient, and proficiencies in new literacies are essential to children's future. Reading online and in traditional texts requires different skills; thus, teachers must adjust their teaching to incorporate online texts and more complex reading strategies and deeper levels of higher order thinking skills than reading a traditional text [4]. Educators must find new ways to address reading and comprehension to include using online tools [1]. Online comprehension skills include the use of hyperlinks on web pages, multimedia such as audio and video clips, advertisements, and virtual reality environments. Teachers have the challenge of integrating these technologies and teaching students online comprehension skills in the classroom.

Additional information about how blended learning changes teaching and learning is necessary so teachers can better understand how to teach using a blended learning model [5]. While research in blended learning is on the rise [6], it has focused mostly on students in higher education. In this study, I explored the successes and challenges teachers face blending technology with literacy instruction and provided suggestions for implementing and sustaining blended learning in the classroom. This study examined what students are doing online in a blended learning model and in their traditional classrooms.

\section{Study Description}

This study took place in three elementary schools: Everbrook Elementary, Allen Park, and Norfolk Elementary (all pseudonyms). All three schools are public schools located adjacent to a city in the southeastern United States. Everbrook and Allen Park were recipients of funding from a nonprofit organization that raised supplementary funds for elementary and middle schools that feed into the high school with the lowest test scores in the district. Blended learning classrooms were created to raise academic performance at these schools. Through blended learning, classrooms could accommodate more students who would be placed with highly effective teachers, with a goal of improving test scores. Teachers were vetted through an interview process that required them to provide student data proving their effectiveness. Selected teachers were paid higher salaries, and had more students (35-40 students) in their classes than an average class (20-25 students). The assumption was that technology would allow the teacher to differentiate and increase instructional impact. Teachers were selected because they taught blended learning in their fifth grade classrooms. The first teacher, Ms. Jacobs, was in her fifth year of teaching at Everbrook Elementary. She has teaching experience in third, fourth, and fifth grades. Ms. Allen, from

Everbrook Elementary, a fifth grade blended learning teacher in her twelfth year of teaching. Prior to her current position, Ms. Allen held several classroom positions and served as a literacy facilitator and an assistant principal. Ms. Nash was the most experienced blended learning teacher, with three years of teaching experience using a blended learning model. She was in her fourth year of teaching and taught fifth grade all four years. In this multiple case study, I used purposeful sampling. Student participants were selected based on their gender, demographics, academic ability, and willingness to be part of the study. I sought a diverse mix of students among the relatively small number included at each school site. The teachers assisted me in selecting students who would provide the richest data. Three students were selected from each classroom, for a total 
of nine study participants. These students were purposefully selected so that the mix of demographics and gender mirrored that of the classroom. The teachers collected parent permission slips from all willing study participants. The teachers then identified groups of students as struggling (low), on grade level (medium), and above grade level (high). One student was selected from each group. I selected three African American females from Everbrook Elementary; two African American Females and one African American Male from Allen Park Elementary; and two Females (one African American and one Hispanic) and one African American Male from Norfolk Elementary. The students selected were not an exact representation of the school's demographics. For example, at Norfolk Elementary, 35\% of students were white but no White students were selected. Permission slips were not sorted based on demographics, so it could be assumed that fewer White students agreed to participate, or that they simply were not chosen during the random selection. The purpose of this study was to examine how teachers were implementing blended learning, to identify activities students were engaged in, and to discover how teaching and learning have changed as a result of a blended learning environment. I used an exploratory multiple case study model [7] to examine how students were taught, what assignments students were given, and what texts they were reading. The research design was developed over six weeks in three different fifth grade blended learning literacy classrooms.

The research is guided by the following questions: 1. What is blended learning as it is enacted in three fifth grade classrooms? 2. In these blended learning classrooms, what online texts and activities are assigned to fifth grade students, and in what types of traditional reading are they participating in the classroom? How do students engage or respond to assigned online activities? 3. Considering these texts and activities, how does blended learning change the teaching and learning of reading? I used multiple data sources: observations, semi-structured interviews with teachers and students, and field notes for triangulation of data collection in order to increase validity of findings. I kept a daily reflective journal (memo) to capture initial thoughts and questions, and to reflect on subjectivity during data collection. During the study, I observed each school and interviewed student participants three times. I kept notes on the observations; interviews were recorded and transcribed within two days. Observations captured students' online activities in their traditional literacy classrooms and blended learning. Using Microsoft Word, I documented field notes of the setting, participants, lessons, and events. With an iPad, I kept a visual record of student activities in the classroom during traditional teaching and blended learning instruction. I also created a chart with two columns to record what was seen and heard in the classroom and to note thoughts and questions for later reflection and possible themes. After the first observation and before the first interview with each student, Ms. Nash and Ms. Jacobs videotaped all three participants separately during blended learning. The purpose of the video was to ask students what they were doing during the clip, and specifically discuss what they were doing during blended learning. During the first interview, the students and I viewed the video and then the students described what they were doing online during the taping. Student responses provided details about what they were doing online, and generated follow-up questions I could ask. Interviews I interviewed each classroom teacher to determine what traditional reading instruction and blended learning look like in the classroom. The initial interviews represented the first face-to-face meeting with

the teacher from Norfolk, and the first discussion with the teacher from Allen Park. Together, the teacher and I determined the appropriate time to observe and interview each student. This process also provided understanding about each teacher's initial thoughts on blended learning in literacy. Each teacher was interviewed again at the end of data collection. The focus was on self-reflection and inquiry about how the teacher participants viewed the effects of blended learning and what instructional changes would be needed. Additional questions addressed how blended learning started and was implemented in each school and classroom. I interviewed each student once per visit for a total of three interviews during the research period. The interviews were semi-structured but followed an interview protocol (see Appendix C). Students answered general questions about themselves during the first interview. The research questions were focused on the types of activities students were assigned in traditional literacy class and during blended learning. The student interviews informed the first two questions in the study. Additionally, I kept a journal (memo) to record thoughts, analysis, questions, and ideas throughout the study. Patterns, codes, and themes began to emerge. After observing each site, I recorded thoughts about the observation, interviews, and themes. As the data were transcribed and analyzed, I recorded codes, themes, and thoughts. The memo was used as a place to record outlines and organizational structures to develop the analysis. The journal contained a record of subjectivity issues that arose during the data collection process. In addition to the observation notes, a memo was used to record any question or evaluations that were not related to the research. Grounded theory was used for comparative data analysis, and initiated analysis as soon as data were collected and concepts were noted [8]. Collected data entered into theory only if they were repeatedly presented (or not presented) in most data collection 
formats (interviews, observations, and field notes). I then grouped concepts to form categories and provide to constant comparison for similarities or differences, as they occurred throughout the study. Open coding, axial coding, and selective coding were used to break down, categorize, and unify the data [8]. The theories generated from this study were: limitations for reading online prevented students from using reading strategies taught in traditional reading classes; the wealth of information provided from the

Internet posed both advantages and challenges; and support for teachers and students in a blended learning environment was imperative to its success.

\section{Research Findings}

Within-case and cross-case analyses were used to connect all three cases. To answer the question, what is blended learning, I used a within-case analysis to address the first and second research questions and to analyze each school, or case. Questions remain about the definition of blended learning. It is defined loosely as a mix of traditional teaching and online learning and as combining face-to-face and online modalities [9] But what does that mean? Is simply reading online rather than reading in a traditional print text considered blended learning? What is the role of higher order thinking in blended learning? In the three cases studied, blended learning activities varied.

\subsection{Within-Case Analysis: Case Study 1}

In the first case study, Ms. Jacobs (a pseudonym) taught literacy using blended learning in a lab rotation model, where students rotated from the traditional classroom setting to a computer lab equipped with Chromebooks. Allen Park compartmentalized its upper-grade teachers; each teacher taught a different subject. Ms. Jacobs taught literacy, but embedded social studies content in her lessons. Ms. Jacobs taught three sections a day, and the students also rotated to the math and science teachers, and her classroom was a mix of fourth and fifth grade students. The fourth grade students in her class were performing at or above grade level, thus they worked well with the fifth grade students, who spanned ability levels. All of Ms. Allen's students participated daily in blended learning, rotating from the traditional classroom to the computer lab. The math and science classes were not blended learning classrooms, but students did have access to iPads or Chromebooks. The other teachers in the school were one-to-one with technology, or had a Chromebook or iPad for each student in the classroom. Most teachers used programmed websites, while some used Google Classroom to create and house student assignments. While the county and her school supported blended learning in the classroom, they did not have the infrastructure to support its implementation because of their lack of experience. Without a clear support network, Ms. Jacobs was forced to learn through trial

and error, which was difficult and time consuming. The students engaged in similar content in the classroom and in blended learning; however, Ms. Jacobs struggled with how to teach the same reading strategies in traditional reading and online texts. Students read the same genres or topics in blended learning and the traditional classroom. They had difficulty using strategies online that they could easily use with traditional texts, such as tracking, or keeping track of their thinking on paper. Major themes from the first case study included: (a) reading online required a different set of strategies and skills than reading traditional texts; thus, the teacher should be responsible for teaching these skills, and (b) while traditional reading was more linear and onedimensional, reading online allowed students to explore an infinite amount of information. Students needed to learn how to read online and how to effectively manage the information available to them.

\subsection{Within-Case Analysis: Case Study 2}

In the second case study, Ms. Allen's fifth grade classroom participated in blended learning using both a classroom and a lab rotation with Chromebooks. The year of the study was Ms. Allen's first year teaching with a blended learning model, and Everbrook did not have a vision for what blended learning should look like. Ms. Allen adjusted her blended learning model and student activities several times during the school year, and moved from a lab rotation model to a classroom rotation model. As blended learning was a new initiative, trial and error was evident throughout the interviews and observations. Similar to adjusting the type of blended learning the students engaged in, Ms. Allen changed how she graded writing assignments as the year went on. At first the students did several writing assignments using a Writer's Workshop model on Google Classroom and Ms. Allen gave them feedback. They submitted their work for feedback as soon as they were finished, which often meant students were submitting assignments at different times, creating a time challenge for their teacher. Allowing inconsistent deadlines did not work because it was difficult for her to give timely feedback to all of the students in both of her blocks. She found if she didn't give them feedback they would "goof off on the Chromebook," so she adjusted her assignments. Instead of choosing any topic and submitting writing pieces when they were

finished, the students began doing assigned writing, mostly short research papers or narrative pieces related to the unit they were reading, which they submitted at the end of the week for grading. Simultaneously, throughout the week during direct instruction, Ms. Allen taught students writing 
strategies that could help them during blended learning. She modeled strategies for reading and comprehending nonfiction. Then, in blended learning, students would use these strategies to create their own research projects. During an observation, Ms. Allen taught boxes and bullets, a strategy where students found the main idea in the text and put it in the box, adding details as bullets underneath. The students in blended learning conducted research for their projects and applied the same strategy online using a note-taking app. Ms. Allen also provided writing lessons based on what she determined the students needed.

These assignments had a rubric attached so students knew how they were graded. When they finished the assignments, students could access Compass Learning, a self-paced program where students learn reading skills through videos, so they were not waiting if they finished their assignments early. Themes from the second case study included the teacher making adjustments to the organizational structure and assignments as needed throughout the year. There was a lack of support for the teacher to implement blended learning successfully. Additionally, Ms. Allen used the blended learning time for Writer's Workshop, ultimately using it in place of a part of balanced literacy in the classroom.

\subsection{Within-Case Analysis: Case Study 3}

In the final case, Ms. Nash taught all subjects to her class of approximately 25 students in a classroom rotation model. She had taught using a blended learning model in literacy for three years, and described her implementation as incremental. The school sent her to several professional development sessions where teachers were given the opportunity to experiment with apps and platforms to discover their preferences. I noted that Ms. Nash's students used the iPads in blended learning as an extension of how they read in the classroom. In observations, students were seen reading texts at their independent reading levels, and on the iPads, students were accessing similar texts using LightSail and Raz-Kids. These programs allowed the teacher to set the level so students had access to texts only on their reading levels. Similarly, Ms. Nash had students pick independent texts from the classroom and school library at their levels. Two themes emerged from the final case study: (a) the teacher successfully implemented blended learning as a result of slow implementation, and support from her school community, and (b) questions remain as to what it means to effectively implement blended learning. Over three years, Ms. Nash gradually implemented blended learning by first experimenting with apps and programs and attending national professional development conferences to learn more about blended learning.
In her third year of implementation, the year of the study, students began to use more programs and became more independent in their use of iPads. Although Ms. Nash reported that students created and chose apps and did not just use the iPad instead of paper texts, observations and interviews did not indicate that the students created content. Questions remained as to the definition of blended learning: Was reading on an iPad considered blended learning? What was considered blended learning?

\subsection{Cross-Case Analysis}

Although some reading strategies are compatible in both traditional and online formats, more applications and programs need to be researched and created for students and teachers to successfully bridge the gap between reading online and reading in traditional text. Ms. Jacobs noted that strategies she taught for reading traditional texts could not be used with the Chromebooks. She preferred that her students monitor their comprehension of a text by tracking their thinking. She wanted them to use their inner voices, or what they thought about the text, and make note of it on paper or sticky notes. In the third case study, students were asked to respond to texts in their journals and on sticky notes, but they did not employ the same strategies while reading online texts. Conversely, in an observation of students reading on iPads in Ms. Jacob's class, students read books using LightSail, where periodically the program required students to answer questions or identify vocabulary words. The students did not respond to the LightSail text as they did to their traditional texts; they answered comprehension questions as they read the text. Some capabilities of online text raised concerns for teachers about student engagement and learning. Ms. Jacobs' class used websites to find information. She allowed students to use hyperlinks to answer specific questions.

Some students observed during the study copied and pasted information without putting it into their own words. One student showed me how he answered questions posed by his teacher by using the copy and paste option. He quickly copied the work of the online author and posted it as his own answer. While this can be done with traditional texts, it took seconds for this student to copy and paste. The ability to copy and paste text is a concern for teachers because little time and effort is required to copy text written by someone else, and it indicates a lower level of thinking. Instead, teachers would prefer to see students summarizing the text in their own words. Ms. Jacobs and Ms. Allen taught students to use strategies with traditional texts, and the students did not apply the same strategies when they read online texts. Ms. Jacobs' students mentioned some strategies that carried over from reading traditional texts to reading online. Rereading is a strategy students used to aid 
comprehension and it can be done with online or traditional texts. Rereading online would require students to scroll back through the text to read again. In the second case study, students said they use sticky notes to track their thinking with both traditional and online texts.

In traditional texts, students used sticky notes to write down their thinking and fixed it to the page. For electronic texts, students generated online sticky notes using Google Keep. Once they had sticky notes on the page in the app, they could move and organize them into groups. Findings also suggest benefits in online reading that changed what it means to read. Students had a wealth of information available to them on the Internet that was both beneficial and challenging to teachers and students. Traditional texts were linear in nature, meaning that students read and thought about the text but only about what was written on the pages. With online texts, students were able to use hyperlinks to explore beyond a text and gain a deeper understanding of a topic. In the first case study, Ms. Jacobs asked her students to explore a Scholastic site where they could click on links and gather more information about the topic they were studying. A student in Ms. Jacobs' class said she could get more details and look up videos for more information on a topic. In the second case, Ms. Allen asked her students to research historical figures using Google and then write sticky notes about the information they found. I observed students using Google to search for relevant information about their subjects.

Support for teachers and students was imperative to the success of blended learning. In the first and third cases, the teachers gradually implemented blended learning and were still using it a year after data collection for the study ended. In contrast, the teacher in the second case study was given little support and she no longer taught using blended learning. Both teachers mentioned that the first year of blended learning was trial and error. They both admit that they grew in knowledge about blended learning and how to make it successful in their classrooms. Teachers in all areas of study had to create content on some level. Blended learning teachers, however, had to plan and create material for both online and traditional activities. When planning traditional reading content, they found many resources available for content support because this kind of reading instruction had been in place for so many years. Blended learning, however, was a new concept, particularly in elementary school, and there was not as much information available. The teachers in the study were both forced to create their own content and to independently research successful applications and programs. Ms. Nash and Ms. Jacobs were more successful than Ms. Allen in implementation because they were able to slowly build their online content. While additional support was needed for teachers, successful implementation required measured implementation and support from the school and district. In contrast, beyond a professional development session in the summer, Ms. Allen did not receive much support in blended learning. In an interview, she mentioned needing additional planning time to create content for her students. She did not have time for necessary teacher tasks as well as blended learning planning and preparation. Ms. Allen would have liked support from a second adult in the room to make sure students were on task and to help with their blended learning assignments. Ms. Allen was the only teacher in the study who did not continue to teach using a blended learning model, perhaps an indication that the lack of support affected the overall sustainability of the program. One argument for blended learning specifically, and technology in the classroom in general, is efficiency. Students can do more and teachers have more flexibility. However, in Ms. Allen's case, the opposite was true. The heavy use of technology plus the lack of support were a burden; they created more work for her, and ultimately, blended learning did not work.

A lack of support for students in blended learning was noted as well. In the third classroom, a student mentioned that she was not able to receive support from the teacher because Ms. Allen was teaching other students during blended learning time. The student said she would go to the Internet or ask the person next to her to find an answer if she had a question during blended learning because Ms. Allen was with a group most of the time. Throughout the three cases in this study, blended learning is illdefined, a cause for confusion that forced teachers to create definitions based on their own experiences. Current research suggests the definition of blended learning is unclear and the findings from this study also revealed different definitions of blended learning.

The teacher in the first case used blended learning as an opportunity for students to expand on the topics studied in Reader's Workshop. Students researched and created Google Slide presentations based on the reading lesson. In the second case, Ms. Allen used blended learning time for students to engage in Writer's Workshop. The students in the final case read on an iPad during blended learning time. Although there is not a clear definition of blended learning, it can be loosely defined as students using technology for the purpose of increasing learning. Two of the three schools in the study used blended learning as a way to increase class size and place good teachers (as measured by student test scores and teacher evaluations) in front of more students in the hope that they can positive affect more students.

This supports the assumption that teachers can be effective if they teach using a blended learning model. In some cases, blended learning can be used to replicate reading with printed text, causing students to 
read using technology in the same way they would read a traditional text. In the third case study, Ms. Nash's students chose a book to read on iPads. LightSail or Raz-Kids included comprehension questions, either throughout the book or at the end. This activity is similar to an assignment where the teacher would give students a passage and ask them comprehension questions at the end. This study also suggests technology can be used to create different learning opportunities, particularly for higher levels of thinking. In the first study, Ms. Jacobs assigned students tasks that allowed them to create content such as Google Slides based on topics they were studying. In contrast, in the third case, students were more focused on recall, a lower-level thinking task, where they were reading and answering comprehension questions based on the text.

Although it is not necessary for students to be at high levels of thinking all the time, it is important to note that technology made it easier for students to research and create because of access to applications and programs with a click of a button. Although computers help students elevate their thinking, when they are used as a substitute for traditional texts, they limit what students can do. Ms. Jacobs expressed concern that her students could not track their thinking as they usually do in the margin of their texts.

For students to truly engage in online learning, teachers must give up some control. Reading online can extend boundaries, and rarely entails reading a single text. Rather, it means navigating a potentially limitless web of texts. Often, websites are visually appealing with videos and moving pictures, and distracting with advertisements and unrelated information. Video and other media on the page can give readers more information to digest, and hyperlinks on one web page can lead a reader to other pages of information about related topics. Both videos and hyperlinks can be interesting for readers, but also distracting if they are not related to the initial research topic.

Reading online text allows students to explore and leaves teachers somewhat helpless as to where that exploration will end. Reading traditional books gives teachers greater control. In the three cases in this study, the teachers maintained much more control and access to the texts students were reading during traditional direct instruction. In the first case, Ms. Jacobs chose the topic and the book the students would read. The students then researched the topic during blended learning. The texts in blended learning were online, so students had access to more information.

The findings in Chapter four revealed what students were doing online in blended learning and in traditional classrooms and how teaching needs to be adjusted based on these findings. Three major themes emerged from the cross-case analysis in this qualitative case study: (a) questions remained about the definition of blended learning; (b) reading online often required a different set of strategies and skills, thus, blended learning changed the way teachers responded to how students learned and understood reading, particularly reading and comprehending online texts; and (c) support for teachers and students was imperative to the success of blended learning. In the final chapter, I will revisit the

findings and will discuss implications and recommendations for further research.

\section{Discussion}

While the ability to discover an immense amount of information is exciting, it can be dangerous if students are not given the tools needed to safely explore. Hyperlinks and media links on web pages can be distracting. Students in Ms. Jacob's class needed instruction on hyperlinks and how they can be helpful, as well as how to use search engines using key words, and how to assess the validity and reliability of a website. Some of Ms. Jacobs' students were cutting and pasting information into Google Slides rather than comprehending and paraphrasing the information. Online reading materials can have limitations when compared to traditional texts [10]. The Common Core State Standards require that students read deeply to understand text. Ms. Jacobs and Ms. Allen taught their students to do close readings, or multiple readings of a complex text to gain deep, comprehensive knowledge. Students were taught to mark the text with their pencils, underline words they did not know, and write summaries of paragraphs in the margins.

These skills did not translate to online texts. Ms. Jacobs expressed concern that students could not track their thinking on the computer as they could in a text. Blended learning can be used to replicate traditional reading, expand thinking, and allow for higher levels of thinking in the classroom [11]. In Ms. Nash's classroom, students read on iPads during blended learning, an activity that could be replicated with traditional texts. They read books on their reading level using Raz-Kids or LightSail. LightSail included intermittent comprehension questions for students to answer as they read, similar to a teacher giving students a passage to read and questions to answer. Blended learning can make researching and organizing materials more efficient. When students were asked to create presentations using the Internet to research a topic, Ms. Allen's students accessed Google Keep to organize information, used virtual sticky notes to sort information into subtopics, and wrote a research paper. Technology in the classroom made it easier for students to research and add to their knowledge of a topic. While students could have done this work using traditional texts, the Internet, hyperlinks, and online resources made it easier for students to think at higher levels by creating content. 
Blended learning can also be used to create higher level thinking tasks [12]. When students read in traditional texts, they wrote their thoughts on sticky notes or in their reading journals. Different demands were placed on students when they use a program that incorporated questions with the text. It forced them to think about what was happening in the text, or required them to reread the text if they were not paying attention. When they were reading a text on their own, students had ownership of what they were thinking about and they continued to read without stopping. Conversely, LightSail incorporated specific questions that challenged students to think about the text while they read. The ultimate reading goal is for students to be able to read and to think critically about content.

If students are asked questions as they read, they may have to think about what they are reading, but they do not learn to think independently about what they are reading. There is a need to bring to the forefront applications and information that support the transition from printed text to online text. While these may exist, teachers at the elementary level are not aware of them and are not using them in their classrooms. Teachers need access to multiple strategies for students to use online applications, resources to help support thinking, and a central place for resources. Students observed in this study did not have strategies for tracking their thinking when reading online. They were unable to highlight and write in margins, or add sticky notes to online texts.

Reading strategies they were taught for reading traditional texts did not translate to online reading. The data from Chapter four indicated the need for more research into whether these types of applications existed. If they do not, I recommended that they be created to make teaching strategies using traditional texts transferrable to online texts. All three teachers in the case studies discussed the importance of having support to successfully implement blended learning. Ms. Jacobs and Ms. Allen reported their schools did not have a clear vision of what blended learning looked like. The schools entered into blended learning thinking it was a good idea, but without knowing how to support implementation. A gradual implementation timeline made two of the teachers feel successful in their implementation of blended learning and they continued with the program the following school year. The one teacher in the study who did not continue with blended learning the following year implemented it quickly, and said she was not successful.

Additional support could be provided for teachers by developing an implementation plan to support the introduction of blended learning. An implementation plan for blended learning is needed. Teachers mentioned that gradual implementation was key in the success of blended learning. The first and third cases in the study had a measured implementation of blended learning and they continued teaching literacy using that same model the following year. The teacher in the second case reported in an interview that she had not received very much support, and there was no vision for blended learning in her school. An established implementation plan may have helped Ms. Allen sustain blended learning at her school. Teachers introducing blended learning were in need of inservice or professional development focused on implementation and creation of materials. This inservice should be created or run by teachers in the field who have first-hand experience with blended learning. Teachers needed a proven implementation plan that worked for other teachers.

Teachers who have successfully applied blended learning in their classrooms could provide examples of beginning of year implementation, and recommendations for a 3-5 year sustainability plan. The plan could include literacy and math websites, learning management systems, examples of teachercreated content, and behavior management strategies. Teachers also needed support with building curriculum, and a database to share successful blended learning curricula. Two teachers in the study successfully implemented blended learning because they had the first year as a trial and error period. Ms. Jacobs successfully built her own curriculum using Google Classroom and Schoology after the first year.

\section{What is Blended Learning?}

Many definitions existed for blended learning, but none of them were clear [13]. In this study, students in one school used iPads to read text and answer questions. The goal of blended learning was to combine the classroom and digital environments. In the third case, the students used iPads to read, and, beyond the application that included comprehension questions, the online activities were similar to classroom activities. In the first two cases, teachers extended learning from the classroom to technology with Chromebooks, whether in the classroom or in a computer lab. Ms. Jacobs asked her students to engage in online scavenger hunts and to create Google Slide presentations that answered questions about civil rights, using technology exclusive of printed resources.

In the second case, Ms. Allen asked her students to research topics related to those studied in class. They used Google's virtual sticky notes to record and organize their thinking. For Ms. Nash, however, the students used technology to read and answer questions on an iPad, and did not extend their thinking. This study suggests there is not yet a clear definition of blended learning; however, in these classrooms both traditional forms of reading instruction and some system of technology application were evident. Students read differently online than they do in traditional texts, and teachers 
need to provide the resources for students to be successful with the change in practice. Support was needed for teachers and students to have a successful blended learning experience.

For teachers to feel supported, they must have quality professional development focused on measured, successful implementation, and information on creating content for blended learning. While this study did not resolve questions about what blended learning is, I suggested steps that institutions can take to support students and teachers who are increasingly using technology to aid teaching in elementary schools.

\section{References}

[1] Lankshear, C., \& Knobel, M. (2006). New literacies (2nd ed.) Maidenhead, UK : Open University Press.

[2] Domingo, M. (2012). Linguistic layering: Social language development in the context of multimedia design and digital technologies. Learning, Media and Technology, 1-27. doi:10.1080/17439884.2012.670645.

[3] Hagood, M.C., Stevens, L.P., \& Reinking, D. (2003). What do THEY have to teach US? Talkin' 'cross generations! In D. Alvermann (Ed.), Adolescents and literacies in a digital world (pp. 68-83). New York: Peter Lang.

[4] Leu, D. J., Kinzer, C. K., Coiro, J. L. \& Cammack, D. W. (2004). Toward a theory of new literacies emerging from the Internet and other information and communication technologies. In Theoretical models and processes of reading (1570-1613). Newark, DE: International Reading Association.

[5] American Association for the Advancement of Science. (1999). Dialogue on early childhood science, mathematics, and technology education. Washington, DC: George D. Nelson.

[6] Drysdale, J. S., Graham, C. R., Spring, K.J., \& Halverson, L. R. (2013). Analysis of research trends in dissertations and theses studying blended learning. Internet and Higher Education, 17, 90100.

[7] Yin, R. K. (2009). Case Study Research: Design and Methods. (4th ed.). Thousand Oaks, CA: SAGE Publications.

[8] Glaser R. B. \& Strauss, F. (1967). The discovery of grounded theory: Strategies for qualitative research. Piscataway, NJ: Aldine Transaction Publishers.

[9] Halverson, Graham, Spring, Drysdale. (2012). An analysis of high impact scholarship and publication trends in blended learning. Distance Education, 33(3), 381-413.

[10] Coiro, J. (2011). Talking about reading as thinking: Modeling the hidden complexities of online reading comprehension. Theory into Practice, 50, 107-115.
[11] Fisher, D. \& Frey, N. (2012). Blended learning. Engaging the adolescent learner, International Reading Association.

[12] Powell, A., Watson, J., Staley, P., Patrick, S., Horn, M., \& Fetzer, L. (2015). Blended learning: The evolution of online and face-to-face education from 2008-1015. Promising practices in blended and online learning series. International association for $\mathrm{K}-12$ online learning.

[13] Abrams, S. S. (2015). Integrating virtual and traditional learning in 6-12 classroom: A layered literacies approach to multimodal meaning making. New York: Routledge. 